\title{
Relationship between Quality of Life and Occupational Accidents in South-East of Iran (Zahedan)
}

\author{
Fereydoon Laal ${ }^{1}$, Mohammad Jafari Modrek ${ }^{2}$, Davoud Balarak ${ }^{3}$, Mahdi Mohammadi ${ }^{4}$, Mahdieh Rakhshani ${ }^{5}$ \& \\ Narges Rigi $i^{3}$ \\ ${ }^{1}$ Department of Occupational Health, Health Promotion Research Center, Zahedan University of Medical \\ Sciences, Zahedan, Iran \\ ${ }^{2}$ Department of Parasitology, School of Medicine, Zahedan University of Medical Sciences, Zahedan, Iran \\ ${ }^{3}$ Department of Environmental Health, Health Promotion Research Center, Zahedan University of Medical \\ Sciences, Zahedan, Iran \\ ${ }^{4}$ Department of Epidemiology \& Biostatistics, Health Promotion Research Center, Zahedan University of \\ Medical Sciences, Zahedan, Iran \\ ${ }^{5}$ School of Health, Zahedan University of Medical Sciences, Zahedan, Iran \\ Correspondence: Mohammad Jafari Modrek, Infection Disease and Tropical Medicine Research Center, Zahedan \\ University of Medical Sciences, Zahedan, Iran. E-mail: mjafarimodrek547@gmail.com
}

Received: April 11, 2016 Accepted: May 18, 2016 Online Published: June 30, 2016

doi:10.5539/gjhs.v9n2p112 URL: http://dx.doi.org/10.5539/gjhs.v9n2p112

\begin{abstract}
With the development of science and technology, occupational accidents, as one of the most important problems in the world, result in negative effects on physical and psychological health, and also the quality of life of workers. The aim of this study was to compare the quality of life among workers with and without accident. In a cross-sectional study, 93 workers were selected, 31 who experienced accident and 62 as control group. To gather the data, a researcher-made questionnaire for demographic characteristics and the quality of life questionnaire (SF-36) were used. Mann-Whitney and Chi-square tests were used for data analysis. The mean and standard deviation of age was $30.81 \pm 7.29$ and $30.56 \pm 7.19$ in workers with accident (case group) and control group, respectively. Homogeneity was ensured in terms of age and work experience and the two groups had no significant difference in this regard $(\mathrm{p}>0.05)$. Most of the participants were high school graduates $(67.7 \%)$. The majority of accidents $(68.8 \%)$ had occurred in the manufacturing sections. The most common accident type was sprayed chemical substances $(19.4 \%)$ and the less frequent was electrocution $(3.2 \%)$. The mean total score for the quality of life was $37.61 \pm 14.29$ and $74.92 \pm 12.95$ in the case and control groups with a statistical significance difference $(p<0.001)$. The results of this study indicate that the incident could affect the quality of life of workers. Therefore, promoting the safety culture can help to reduce the occupational accidents.
\end{abstract}

Keywords: quality of life, occupational accidents, physical health, mental health

\section{Introduction}

Work has always been a part of people's lives and is considered as a value. People believe that work can be a way to provide good financial condition, reputation, respect and economic progress. For living, every person needs to choose a job which may have potential risks for individual health and due to an increasing rate of occupational accidents in the industries; risks should be considered as a main concern in working conditions (Smith, 2012; Agh, 2014). A review of the previous studies on the condition of mental health in people aged more than 15 years old indicate that about 21 percent of people of society suffer from psychological disorders and women are more vulnerable compared to men (Zare, 2013). Therefore, the quality of life of employees has become one of the most important goals of the organizations and its personnel (Almasi, 2011). Nowadays in medical sciences, the focus is on the health-related quality of life including subjective assessment of current health status and sanitary activities for promoting general level of health allowing the person to pursue valuable life goals. Evaluating the relationship between different factors and quality of life can also provide a solution for developing health plans (Mansour, 2003; Mandani, 2013). Although valid information on occupational accidents is not available in all countries, the rates of accidents range between 10.4 and 83 million cases per year, 
worldwide. In Europe, the accident rate is 10.4 to 29.7 million per year compared to 27.0 in Asia. Occupational accidents are the third main cause of death worldwide, and are considered as one of the most important health, social, and economic risks both in industrialized and developing countries. According to the International Labor Organization (ILO) report, approximately 270 million workers suffer from job damages, and 2 million experience deaths annually worldwide. A research on the job injuries in Korea between 2001 and 2010, illustrated that non-fatal occupational injuries have been higher in the manufacturing sector while the fatal occupational injuries was higher in the construction sector (Agh, 2014; Trgovcevic, 2014). Deaths from diseases and occupational injuries in all countries has exceeded not only the rate of mortality from common illnesses and AIDS, but also incurs high economic, social and family costs equivalent to $4 \%$ decrease of GDP and 2.8 million USD for direct and indirect costs of disease worldwide (Gonzalez-Delgado, 2015). High-risk factors of depression are repeated accidents in life, stress, weak social support, and also lower socio -economic ability (Shaku, 2015). Upper extremity injuries (UEIs) have been proposed as one of the leading work-related causes of disability in the adult population, resulting in loss in large-scale manufacturers (Hou, 2013; De Putter, 2014). Also, chronic lung disease is one of the most common medical conditions among chemical affected victims (Saeed, 2014). Health-related quality of life (HRQOL) has influenced largely the economic and social relations (Hyphantis, 2014) and SF-36 is now used widely for assessment of HRQOL (Chen, 2015). One of the concerns of employees is workplace hazards that may affect their quality of life (15) because occupational injuries and diseases lead to different complications that even affect everyday life. Although many studies have been done on work-related accidents but regarding the lack of resources available, there are limited studies on its relationship with quality of life in Iran. So, this study aims to address this topic in two different industries in Zahedan, the scores of quality of life in these industries can be useful for health planning in order to improve the quality of life.

\section{Materials and Methods}

This study type is cross-sectional. The population included 300 workers in flour products and agricultural pesticides factories of Zahedan. According to research criteria, all eligible injured people were considered as case group $(\mathrm{n}=31)$ and 62 people (controls) were selected randomly form all remaining eligible individuals. The control group was selected homogenous in terms of age and years of work to the case group. All cases had accident during activity in the working projects in the past 5 years (2011-2015) so that their accident was recorded in the Immunity and Health Unit of factories. Accidents were defined as those upon which an emergency condition had occurred for the injured person who required medical care, and leaded to losing at least one working day. The control group consisted of those who were currently working in these factories and have not had an accident yet. Workers with a number of factors which disrupt the quality of life such as chronic cardiovascular disease, diabetes, cancer, kidney disease, hemodialysis, respiratory failure, multiple sclerosis disorder and drug addiction or a family member, as well as divorced people were excluded from the population of this study (Almasi, 2011; Barkhordari, 2010). To gather the data, a researcher-made demographic questionnaire and quality of life survey (SF-36) was used to measure eight dimensions of the quality of life (Mandani, 2013). These dimensions are: physical function (10 items), role limitations due to physical problems (4 items), role limitations due to emotional problems ( 3 items), vitality (4 items), mental health (5 items), social functioning ( 2 items), bodily pain ( 2 items), general health (5 items); with the exception of a question that measures the change in one's health status over a one year period. Physical functioning, role limitations due to physical problems, bodily pain, general health in the dimension of total physical health and role limitations due to emotional problems, vitality, mental health and social functioning in the dimension of mental health are collected. In this study, subjects were assessed by the questionnaire in terms of both mental and physical function. With this questionnaire, the tool determines an overall score, which indicates the score of the quality of people's lives. All dimensions and mean scores range between (0-100) where a higher score, showed higher quality of life (Barkhordari, 2010; Makkar, 2015; Farahani Nia, 2012). The 36-items form of this questionnaire was designed by War and Sherborn in 1992 in America (Gharibi, 2015). Its validity and reliability were examined in various groups. The reliability and validity of the translated Persian questionnaire in Farsi was evaluated by Montazeri et al. in 2005 (Mandani, 2013). Questionnaires were distributed between the two groups of employees and they were asked to complete it. The data analysis was performed using software Spss22. The significance level was considered 0.05 . Age, work experience, total quality of life and its subscales were not normally distributed in each study groups based on Shapiro-wilk test. Therefore Mann-Whitney U test along with Chi-square test were used to analyze the data. There was no missing value for variable measured. 


\section{Results}

According to the results of this study, mean score of age in cases and controls were $30.81 \pm 7.29$ and $30.56 \pm 7.19$ years, respectively. Also, the mean of work experience in the two groups were $6.29 \pm 5.31$ and $5.97 \pm 4.76$, respectively. According to Table 1, two groups had statistically no significant difference in terms of age and work experience.

Table 1. Homogenization of studied groups in the flour and pesticide agriculture factories in 2015

\begin{tabular}{llll}
\hline Variable & $\begin{array}{l}\text { Control Group }(\mathrm{N}=62) \\
\text { Mean } \pm \text { Sd }\end{array}$ & $\begin{array}{l}\text { Case Group }(\mathrm{N}=31) \\
\text { Mean } \pm \text { Sd }\end{array}$ & $\mathrm{P}$ \\
\hline Age & $30.56 \pm 7.19$ & $30.81 \pm 7.29$ & 0.877 \\
Work Experience & $5.97 \pm 4.76$ & $6.29 \pm 5.31$ & 0.948 \\
\hline
\end{tabular}

$\mathrm{SD}=$ Standard deviation.

According to Table 2, there were $71 \%$ and $32.3 \%$ men in the case and control groups respectively. Most workers in two groups were married with middle economic level. Working sections included production, warehouse and storage unit. Table 2 shows that a significant difference exists between the two groups in terms of gender, education level and working unit $(\mathrm{p}>0.05)$; while the economic situation and marital status had not significant differences $(\mathrm{p}<0.05)$.

Table 2. Demographic characteristics of subjects in the two groups

\begin{tabular}{|c|c|c|c|c|c|c|}
\hline \multirow{2}{*}{ Demographic } & & \multicolumn{2}{|c|}{ Control group $(n=62)$} & \multicolumn{2}{|c|}{ case group $(n=31)$} & \multirow{2}{*}{$\mathrm{P}$} \\
\hline & & $\mathrm{N}$ & percent & $\mathrm{N}$ & percent & \\
\hline \multirow{3}{*}{ Sex } & Man & 20 & 32.3 & 22 & 71.0 & \multirow{3}{*}{$<0.001$} \\
\hline & Woman & 42 & 67.7 & 9 & 29.0 & \\
\hline & Under Diploma & 7 & 11.3 & 10 & 32.3 & \\
\hline \multirow[t]{3}{*}{ Level of education } & Diploma & 46 & 74.2 & 17 & 54.8 & \multirow[t]{3}{*}{0.046} \\
\hline & Higher than diploma & 9 & 14.5 & 4 & 12.9 & \\
\hline & Weak & 11 & 17.7 & 4 & 12.9 & \\
\hline \multirow[t]{3}{*}{ economic situation } & Medium & 31 & 50.0 & 23 & 74.2 & \multirow[t]{3}{*}{0.068} \\
\hline & Good & 20 & 32.3 & 4 & 12.9 & \\
\hline & Installation & 5 & 8.1 & 9 & 29.0 & \\
\hline \multirow[t]{2}{*}{ Working unit } & Production & 47 & 75.8 & 17 & 54.8 & \multirow[t]{2}{*}{0.025} \\
\hline & Warehouse & 10 & 16.1 & 5 & 16.1 & \\
\hline \multirow{2}{*}{ marital status } & Single & 10 & 16.1 & 4 & 12.9 & \multirow{2}{*}{0.768} \\
\hline & Married & 52 & 83.9 & 27 & 87.1 & \\
\hline
\end{tabular}

$\mathrm{N}=$ the number of persons in each group.

Most incident time (38.7 percent) was between 11a.m. and 13p.m. The highest frequency of accidents was related to the spraying of chemicals, cuts and falling objects with 19.4, 16.12, and 12.9 percent, respectively; and the lowest frequency of accidents was electrocution (3.2 percent). According to Table 3 , the frequency of other accidents is $19.38 \%$ including bone dislocation and explosion of chemical bottles, which are not very frequent and categorized as other. The main cause of accidents was unsafe acts by the workers (58.1). Mean wasted days was $12.68 \pm 8.81$. 
Table 3. Accident-related factors in the case group

\begin{tabular}{llll}
\hline \multirow{2}{*}{ Factors associated with the accident } & & \multicolumn{2}{l}{ case group $(\mathrm{n}=31)$} \\
\cline { 3 - 4 } occurrence time & $9-11$ & $\mathrm{~N}$ & Percent \\
\hline \multirow{3}{*}{ Accident type } & $11-13$ & 11 & 35.5 \\
& $13-15$ & 12 & 38.7 \\
& Fall from height & 8 & 25.8 \\
& electrocution & 2 & 6.5 \\
& Hurtle & 1 & 3.2 \\
& Foul & 3 & 9.7 \\
& Falling objects & 2 & 6.5 \\
& spraying of chemicals & 2 & 6.5 \\
& Slippage & 6 & 19.4 \\
& Cuts & 4 & 12.9 \\
& Other cases & 5 & 16.12 \\
Cause of the accident & Unsafe acts & 6 & 19.38 \\
& Unsafe condition & 18 & 58.1 \\
& Lack of use PPE & 11 & 35.5 \\
\hline
\end{tabular}

$\mathrm{N}=$ the number of persons in each group.

As shown in Table 4, there was a significant difference between the mean of physical health in case $(31.10 \pm 15.60)$ and control $(72.64 \pm 14.94)$ groups. The mean of mental health in case and control groups, was $41.78 \pm 14.36$ and $74.58 \pm 14.47$, respectively $(p<0.001)$. Finally, the total mean scores of both dimensions (physical health and mental health) were significantly different in the two groups, $37.61 \pm 14.29$ and $74.92 \pm 12.95$ $(\mathrm{p}<0.001)$. According to the results presented in Table 4, all dimensions are statistically different.

Table 4. Comparison between the mean scores in the eight dimensions of quality of life in the case and control groups

\begin{tabular}{|c|c|c|c|c|}
\hline \multirow{2}{*}{\multicolumn{2}{|c|}{ Dimension of quality of life }} & Case group $(\mathrm{n}=31)$ & Control group $(\mathrm{n}=62)$ & \multirow{2}{*}{$\mathrm{P}$} \\
\hline & & Mean \pm SD & Mean \pm SD & \\
\hline \multirow{5}{*}{ physical health } & Physical functioning & $35.32 \pm 21.64$ & $80.40 \pm 21.60$ & $<0.001$ \\
\hline & Role-Physical & $16.13 \pm 21.94$ & $77.82 \pm 25.25$ & $<0.001$ \\
\hline & Bodily Pain & $33.63 \pm 25.24$ & $62.66 \pm 23.23$ & $<0.001$ \\
\hline & General Health & $39.31 \pm 14.53$ & $69.68 \pm 15.06$ & $<0.001$ \\
\hline & Total Physical Health & $31.10 \pm 15.60$ & $72.64 \pm 14.94$ & $<0.001$ \\
\hline \multirow{5}{*}{ Mental health } & Role-Emotional & $11.83 \pm 16.21$ & $80.64 \pm 26.69$ & $<0.001$ \\
\hline & Vitality & $54.19 \pm 18.93$ & $73.71 \pm 28.84$ & $<0.001$ \\
\hline & Mental Health & $57.16 \pm 18.48$ & $75.03 \pm 18.00$ & $<0.001$ \\
\hline & Social Functioning & $43.95 \pm 20.88$ & $68.95 \pm 22.49$ & $<0.001$ \\
\hline & Total mental health & $41.78 \pm 14.36$ & $74.58 \pm 14.47$ & $<0.001$ \\
\hline \multicolumn{2}{|c|}{ Total mean scores of quality of life } & $37.61 \pm 14.29$ & $74.92 \pm 12.95$ & $<0.001$ \\
\hline
\end{tabular}

$\mathrm{SD}=$ Standard deviation.

\section{Discussion}

In this study, to eliminate the confounding factors of age and experience homogeneity was run in the two groups. Similar studies such as Bylund (Bylund, 1998) and Wadsworth (Wadsworth, 2003) showed that the rate of accidents is reduced with age and experience increase. The Yazdi Moadam showed that aging can reduce the quality of life score (Moghadam, 2006). In addition, based on the results, there was no significant difference 
between the two groups in terms of marital status, and socioeconomic status. It is recommended in future studies to investigate the events and the quality of life better other confounding factors such as sex, education level, etc. must be synchronized. In this study, most accidents occurred in production units that are inconsistent with the results by Kadir Cicek (Cicek, 2013). In his study, the highest rate of accidents occurred in repair unit. Therefore, engineering and management tools such as preventative maintenance should be employed due to the high frequency of accidents in this unit. Most of the accidents occurred in men, high school diploma, average economic situation and married people. Another cause of this finding can be that of the higher presence of married men in the study. Also, the economic situation of majority of subjects was at an intermediate level due to the economic downturn in those industries. Regarding the results of this study, the quality of life in the physical and mental health dimensions had a significant difference in the case and control groups, which is consistent with Agh study (Agh, 2014). Also in Laurent research results showed life satisfaction and quality of life were significantly impaired in stroke patients, compared with controls and Quality of life was strongly correlated with functional independence and depressive mood (Laurent, 2011). A study by Barkhordari, et al. which aimed to investigate the relationship between quality of life and the accidents, the results showed that the mean scores of quality of life there is a significant difference between the two groups in two physical pain and role limitations (Barkhordari, 2010). In a study by Claudia Maria Monterio et al. in 2009 on the victims of accidents, the difference was statistically significant in the dimension of physical pain (Monteiro, 2009). Also, in the study by Jason Noble there was a significant difference in the role limitation that is consistent with the present results (Noble, 2006). In fact, the ability and power to do a function i.e. the physical health is significant in both groups and more attention should be given to this issue in industrial environments. According to the suggestions of Gabrielle Pucci et al. one way to improve the quality of life can be continuous and regular physical activity in the lives of people (Pucci, 2012). Employing people with the right qualifications for the jobs is one of the main objectives of health professionals in occupational environments which can improve the quality of life and reduce accidents in this area. This can reduce stress and increase physical health and ability of people. Basically, when the individual has the greatest adaptation with the world around him, he can have better mental health and vitality in the workplace. According to the results, in mental health dimension there was a significant difference between the two groups in all dimensions similar to results of Agh except for the limitations of role (Agh, 2014). A person suffering from the physical pain and role limitations due to physical and mental problems in the workplace cannot have a good sense of vitality or good feeling. This issue can provide the grounds for the occurrence of accidents in the workplace; the finding regarding the vitality dimension is consistent with Peel and inconsistent with the results of Barkhordari (Peell, 2005; Barkhordari, 2010). Peel $\mathrm{Pb}$ in a study reported higher prevalence of depression symptoms in injured people compared to the normal people (Peell, 2005).

\section{Conclusion}

In this study, the mean scores of overall physical health and mental health of quality of life in injured people had a significant difference compared to those without accidents. Poor working conditions and unsafe acts in most industries affect the frequency of occupational accidents. The results evidence that unsafe acts and conditions and injuries caused by work-related accidents, can affect workers health and reduce quality of their life. Therefore, further research is necessary to design specific methods and tools to understand to what extent occupational injuries affect the quality of life of hurt people and how this effects change their lives. The majority of accidents are preventable. Therefore, accident prevention programs, such as the use of personal protective equipment to prevent exposure to harmful chemical agents, teaching safety principles on the job training courses, and monitoring staff performance can reduce occupational accidents and resulting deaths. So the first step should be to try to prevent the occurrence of accidents. Also pushing senior managers toward holding training seminars, applying the rule of law, upgrading the specialists of the occupational health and safety, should become the priorities the agenda of public health policy. Those involved in health and safety issues of society that their main task is to promote public health, have an important role in preventing these kinds of accidents in the industries. Providing and developing educational programs via communication channels including radio, television, newspapers and local and national training before employment can create a culture of safety in the workplace and in the environment. Implementation of immunity culture not only reduces the risk of accidents, but also has economic and financial interests that represent the long-term return on investment to the organization. Therefore, addressing the issue of improving the quality of life for workers in industrial environments shall be considered as the first step in providing health services and occupational medicine. Paying attention to this issue not only reduces occupational accidents but also is effective in increasing productivity and production, job satisfaction and reduction of mental and physical diseases. Observational studies which identify the most appropriate solutions to improve quality of life, especially among those who are most frequently exposed to occupational accidents are essential. 


\section{Acknowledgements}

The authors would like to express their gratitude toward the Zahedan University of Medical Sciences for funding this research.

\section{Competing Interests Statement}

The authors declare that there is no conflict of interests regarding the publication of this paper.

\section{References}

Agh, M., Mirzaei, R., \& Mohammadi, M. (2014). Study of the Relationship between Life Quality and Occupational Accidents in Wood Industry. Health Scope, 3(1), 1-5. http://dx.doi.org/10.17795/jhealthsco pe-13934

Almasi, H., Lotfollahi, M., \& Zarei Yazdani, M. (2011). Quality of work life and employee performance. Journal of Business Management, 9, 81-101.

Barkhordari, A., Shirazi, G., Halvani, G. H., Fallahzade, H., Sabz makan, L., \& Montazeri, A. (2010). Relationship between quality of life and work-related accidents in Lorestan dam and hydropower plant In 2010, 2(1), 44-50.

Bylund, P.-O., \& Björnstig, U. (1998). Occupational injuries and their long term consequences among mechanics and construction metal workers. Safety Science, 28(1), 49-58. http://dx.doi.org/10.1016/S0925 -7535(97)00070-2

Chen, C. M., Tsai, C. C., Chung, C. Y., Chen, C. L., Wu, K. P., \& Chen, H. C. (2015). Potential predictors for health-related quality of life in stroke patients undergoing inpatient rehabilitation. Health and quality of life outcomes, 13(1), 1-10. http://dx.doi.org/10.1097/01.JHQ.0000462680.47759.53

Cicek, K., \& Celik, M. (2013). Application of failure modes and effects analysis to main engine crankcase explosion failure on-board ship. Safety Science, 51(1), 6-10. http://dx.doi.org/10.1016/j.ssci.2012.06.003

De Putter, C. E., Selles, R. W., Haagsma, J. A., Polinder, S., Panneman, M. J. M., Hovius, S. E. R., \& van Beeck, E. F. (2014). Health-related quality of life after upper extremity injuries and predictors for suboptimal outcome. Injury, 45(11), 1752-1758. http://dx.doi.org/10.1016/j.injury.2014.07.016

Farahani Nia, M., Maleki, M., \& Khayeri, F. (2012). Factors Associated with Quality of Life in People with Lower Limb Amputations. Iran Journal of Nursing (IJN), 25(75), 32-44.

Gharibi, M., Sanagouymoharer, G., \& Yaghoubinia, F. (2015). The Relationship between Quality of Life With Marital Satisfaction in Nurses in Social Security Hospital in Zahedan. Global journal of health science, 8(2), 178. http://dx.doi.org/10.5539/gjhs.v8n2p178

Gonzalez-Delgado, M., Gómez-Dantés, H., Fernández-Niño, J. A., Robles, E., Borja, V. H., \& Aguilar, M. (2015). Factors associated with fatal occupational accidents among Mexican workers: A national analysis. PloS one, 10(3), 1-19. http://dx.doi.org/10.1371/journal.pone.0121490

Hou, W. H., Liang, H. W., Sheu, C. F., Hsieh, C. L., \& Chuang, H. Y. (2013). Return to work and quality of life in workers with traumatic limb injuries: A 2-year repeated-measurements study. Archives of physical medicine and rehabilitation, 16(1), 703-710. http://dx.doi.org/10.1016/j.apmr.2012.10.033

Hyphantis, T. (2014). The influence of the current recession on mental health and quality of life in people with chronic medical conditions seeking urgent care in Greek Accident and Emergency Departments. Journal of Psychosomatic Research, 76(6), 505. http://dx.doi.org/10.1016/j.jpsychores.2014.03.050

Laurent, K., De Sèze, M. P., Delleci, C., Koleck, M., Dehail, P., Orgogozo, J. M., \& Mazaux, J. M. (2011). Assessment of quality of life in stroke patients with hemiplegia. Annals of physical and rehabilitation medicine, 54(6), 376-390. http://dx.doi.org/10.1016/j.rehab.2011.06.002

Makkar, V., Kumar, M., Mahajan, R., \& Khaira, N. S. (2015). Comparison of Outcomes and Quality of Life between Hemodialysis and Peritoneal Dialysis Patients in Indian ESRD Population. Journal of clinical and diagnostic research: JCDR, 9(3), OC28.

Mandani, B., \& Fakhri, A., (2013). Health-related quality of life in veterans with post-traumatic stress disorder. Veteran Medical Journal, 5(2), 18-25.

Mansour, M., Kotagal, E., Rose, U., Ho, B., Brewer, M., Roy, D., ... DeWitt, T. G. (2003). Health-related quality of life in urban elementary schoolchildren. Pediatrics, 111(6), 1372-1381. http://dx.doi.org/10.1542/ peds.111.6.1372 
Monteiro, C. M., Benatti, M. C., \& Rodrigues, R. C. (2009). Occupational accidents and health-related quality of life: A study in three hospitals. Rev Lat Am Enfermagem, 17(1), 101-7. http://dx.doi.org/10.1590/S0104 $-11692009000100016$

Noble, J., Gomez, M., \& Fish, J. (2006). Quality of life and return to work following electrical burns. Burns, 4, 159-164. http://dx.doi.org/10.1016/j.burns.2005.08.022

Peell, Pb., \& Tolleru, D. J. (2005). Depression and occupational injury: Result of a pilot investigation. J ovvup Environ Med, 47(47), 42-47. http://dx.doi.org/10.1097/01.jom.0000158700.50594.0f

Pucci, G., Reis, R. S., Rech, C. R., \& Hallal, P. C. (2012). Quality of life and physical activity among adults: Population-based study in Brazilian adults. Quality of Life Research, 21(9), 1537-1543. http://dx.doi.org/ 10.1007/s11136-011-0083-5

Saeed, K. B., Parandeh, A., Alhani, F., \& Salaree, M. M. (2014). Health-related quality of life of chemical warfare victims: An assessment with the use of a specific tool. Trauma monthly, 19(1), 1-6.

Shaku, F., Tsutsumi, M., Miyazawa, A., Takagi, H., \& Maeno, T. (2015). Self-care behavior when suffering from the common cold and health-related quality of life in individuals attending an annual checkup in Japan: A cross-sectional study. BMC family practice, 10(3), 1-7. http://dx.doi.org/10.1186/s12875-015-0300-3

Smith, D., Todd, M., \& DeJoy, D. (2012). Occupational injury in America: An analysis of risk factors using data General Social Survey (GSS). Journal of safety research, 43(1), 67-74. http://dx.doi.org/10.1016/j.jsr.2011. 12.002

Trgovcevic, S., Milicevic, M., Nedovic, G., \& Jovanic, G. (2014). Health condition and quality of life in persons with spinal cord injury. Iranian journal of public health, 43(9), 1229-1238.

Wadsworth, E., Simpson, S., Moss, S., \& Smith, A. (2003). The Bristol Stress and Health Study: Accidents, minor injuries and cognitive failures at work. Occupational Medicine, 53(6), 392-7. http://dx.doi.org/10. 1093/occmed/kqg088

Yadzi Moghadam, H., Estaji, Z., \& Heydari, D. (2006). Assessment quality of life of nurses in hospitals of Sabzevar in 84-85. Jornal of Sabzevar University of Medical Sciences, 16(1), 50-56.

Zare, S., Shabani, N., Babaei, A., Heydarabadi, M., Asghari, R., Aminizadeh, V., ... Mohamadi. (2013). Investigation of the Relationship between General Health and Workers' Sleep Quality and Work Incidence in Gole GoharMineralIndustries Co., Sirjan. Scientific Journal of Ilam University of Medical Sciences, 21(2), 112-119.

\section{Copyrights}

Copyright for this article is retained by the author(s), with first publication rights granted to the journal.

This is an open-access article distributed under the terms and conditions of the Creative Commons Attribution license (http://creativecommons.org/licenses/by/3.0/). 